\title{
O tema biodiversidade em artigos do encontro de pesquisa em educação ambiental na perspectiva fleckiana
}

Esse artigo é parte de uma pesquisa de mestrado norteado pela seguinte questão: Que estilos de pensamento sobre biodiversidade circulam nos artigos do Encontro de Pesquisa em Educação Ambiental-EPEA e como se vinculam a Educação Patrimonial Ambiental? O objetivo foi analisar as contribuições epistemológicas de Fleck no contexto da Educação Patrimonial Ambiental publicadas no EPEA acerca de biodiversidade. $O$ trabalho foi viabilizado por meio de pesquisa bibliográfica em ambiente virtual, sites do EPEA, específicos para cada evento. Os artigos selecionados foram de seis encontros, no período de 2001 a 2011 e seguiram alguns critérios da análise de conteúdo estabelecidos por Bardin. Com base na espistemologia Fleckiana identificamos onze estilos de pensamento sobre biodiversidade, quais sejam: Patrimonial Ambiental; Utilitarista; Sistêmico; Naturalista/ecológico/biológico; Humanista; Ambiental Critica; Cultural; Conservacionista; Científico; Resolutivo; Sustentável. Os resultados da pesquisa indicam que alguns estilos circulam nos coletivos de pensamentos esotérico (os autores) e exotérico (estudantes e comunidades pesquisados). A Educação Patrimonial Ambiental esteve vinculada aos artigos do EPEA como Estilo de Pensamento que retratou a preocupação com a biodiversidade enquanto patrimônio natural, cultural e biológico.

Palavras-chave: Estilos de Pensamento; Biodiversidade; Educação Patrimonial Ambiental.

\section{The topic biodiversity in articles of the research meeting on environmental education in the fleckian perspective}

\begin{abstract}
This article was guided by the following question: What styles of thinking about biodiversity circulating in articles Research Meeting on Environmental Education EPEA and how they link to the Environmental Heritage Education? Aiming to analyze the epistemological contributions Fleck in the context of the Environmental Heritage Education published in EPEA about biodiversity. The work made possible through a literature search in a virtual environment, the EPEA sites, specific to each event. Selected articles were the last six meetings in the period 2001-2011 and followed some of the content analysis criteria established by Bardin involving the organization of the analysis, coding, categorization and inference. Based on the epistemology of Fleck (2010) identified eleven styles of thinking about biodiversity. Namely: Asset Environmental; utilitarian; systemic; Naturalist / ecological / biological; humanist; Environmental Criticism; cultural; conservationist; scientific; Resolutivo; Sustentável. Totalizando a collective of 28 researchers who presented papers on biodiversity in the EPEA. In this context the approach of Environmental Heritage Education has been identified as one of the styles of thought on the topic biodiversity. The survey results indicate that some styles circulating in collectives exoteric and esoteric thoughts The Environmental Heritage Education was linked to the EPEA items like thinking style that portrayed the concern for biodiversity as natural, cultural and biological.
\end{abstract}

Keywords: Styles of Thought; Biodiversity; Environmental Heritage Education;

Topic: Fundamentos de Biodiversidade

Reviewed anonymously in the process of blind peer.

Emlly Hanna Silva

Universidade Federal do Pará, Brasil. http://lattes.cnpq.br/4359558768529925 emlly.nicole@yahoo.com.br
Received: 05/10/2016

Approved: 15/01/2017
Referencing this:

SILVA, E. H.. O tema biodiversidade em artigos do encontro de pesquisa em educação ambiental na perspectiva fleckiana. Revista IberoAmericana de Ciências Ambientais, v.8, n.2, p.49-60, 2017. DOI: http://doi.org/10.6008/SPC2179-6858.2017.002.0004 


\section{INTRODUÇÃO}

Esse artigo é fruto de uma pesquisa de mestrado e apresenta os resultados da análise dos artigos de biodiversidade de seis Encontros de Pesquisa em Educação Ambiental-EPEA, entre o período de 2001 a 2011. O EPEA trata-se de um encontro bienal que se constitui a partir de proposições estabelecidas pela comunidade científica, no que tem buscado respostas e proporcionado discussões sobre os seguintes temas: "Tendências e Perspectivas da Educação Ambiental", "Abordagens Epistemológicas e Metodológicas", "Práticas de Pesquisa em Educação Ambiental no Brasil", "Questões Epistemológicas Contemporâneas: O debate Modernidade/Pós-modernidade", "O campo da Pesquisa em Educação Ambiental", "Pesquisa em Educação Ambiental e a Pós-Graduação no Brasil".

A pesquisa utiliza bases da epistemologia Fleckiana que tratam do Estilo de Pensamento construído por meio dos saberes provenientes do coletivo de pensamento, seja qual círculo for, do esotérico ou do exotérico. O primeiro refere-se a um grupo que possui um conhecimento especializado em um determinado tema como, por exemplo, a Biodiversidade: “o público ao qual se dirige é especializado, com um conteúdo específico e com um código fechado, em relação à informação transferida" (ALVETI e CUTOLO, 2001, p.2). Mas, em torno desse círculo ou grupo, forma-se outro círculo maior chamado exotérico que, de acordo com Fleck (2010), é constituído por "leigos instruídos" no conhecimento científico, ou seja, estudiosos de áreas afins que, por exemplo, se identificam com o tema Biodiversidade: "tem-se ainda nesse caso, um público especializado, embora não necessariamente naquele domínio específico" (ALVETI e CUTOLO, 2001, p.2). Esta pesquisa analisa um círculo esotérico uma vez que envolve pesquisadores que estudaram o tema Biodiversidade. O Estilo de Pensamento fleckiano tem três características principais: 1- corresponde a um direcionamento, uma orientação específica para a investigação; 2- constitui-se dos dogmas de determinado campo científico, conectando as práticas investigativas destes à tradição correspondente; 3- possui um caráter transitório.

Historicamente, os conceitos de Biodiversidade circulados na literatura científica, evidenciavam a destruição da Biodiversidade que, diante da questão, os especialistas solicitavam providências para contê-la. Esse ver formativo possibilitou discussões ampliadas em eventos internacionais onde líderes mundiais se preocupavam com a perda da Biodiversidade a nível global estabelecendo-se prazos para os países reduzirem o nível de exploração da Biodiversidade. Esse movimento estabeleceu o rompimento com a ilusão de que tudo parecia fácil de ser interpretado.

A dinâmica das discussões sobre Biodiversidade possibilitou a compreensão do processo de instauração, extensão e transformação do assunto Biodiversidade. De acordo com Fleck (2010), a instauração está relacionada à implementação do Estilo de Pensamento que tem a ver com as ideias iniciais sobre o assunto Biodiversidade, que eram discutidas apenas entre os naturalistas. Já a extensão trata da ampliação do estilo, como ocorreu durante a ECO-92, quando o tema foi amplamente divulgado pela mídia impressa e televisiva. Por último, a transformação acontece quando surge a complicação, ou seja, outra forma de pensar, que gera outro Estilo de Pensamento. Nesse sentido, o tema Biodiversidade tem assumido várias vertentes 
ou estilos, tais como a visão econômica, política, social, cultural etc., rompendo com a ideia inicial dos naturalistas, em que o tema Biodiversidade atrelava-se apenas a aspectos naturais e ecológicos. $\mathrm{Na}$ epistemologia fleckiana o processo de construção do conhecimento científico da referida temática vem ser entendido como desenvolvimento de um fato científico, posta que se trata de:

Uma relação de conceitos conforme o Estilo de Pensamento, que, embora possa ser investigável por meio dos pontos de vista históricos e da psicologia individual e coletiva, nunca poderá ser simplesmente construída, em sua totalidade, por meio desses pontos de vista. Assim, fica constatado o fenômeno da associação inseparável das partes ativas e passivas do saber, e ainda o fenômeno de o número das duas partes crescer com o número dos fatos (FLECK, 2010, p.132, destaque do autor).

$\mathrm{Na}$ epistemologia fleckiana, o fato científico interliga conceitos após a generalização e, mais tarde, os especialistas passam a ter dúvidas, provocando a quebra da harmonia de pensamento. Exemplos disso são as permanentes discussões acerca dos resultados causados pelas interferências humanas no meio ambiente provocando nos especialistas dúvidas quanto à veracidade e à eficiência de algumas intervenções, gerando com isso a quebra da harmonia das ilusões no interior do círculo esotérico. A constatação de que um só ponto de vista sobre a biodiversidade já não é eficiente gera incerteza, complicação e dúvidas entre os especialistas; consequentemente, a harmonia das ilusões é rompida, dando lugar a novos estilos de pensamento, gerando um acoplamento ativo. "Qualquer descoberta empírica, portanto, pode ser concebida como complemento, desenvolvimento e transformação do Estilo de Pensamento" (FLECK, 2010, p. 142).

Assim, as novas percepções relacionadas ao conceito de biodiversidade, provoca transformação no Estilo de Pensamento dado as evoluções do conhecimento científico. $O$ assunto deixa de ser objeto de estudo de naturalistas (acoplamento passivo) para novos especialistas como o ocorrido por ocasião da ECO-92 em que foi possível perceber que o tema Biodiversidade surge em várias dimensões que necessitam de aprofundamento, tais como cultural, social, patrimonial, econômico, ambiental, havendo, neste caso, acoplamento ativo e acontecem novos Estilos de Pensamento. As discussões que abordam Biodiversidade vêm sendo amplamente debatidas bem antes da ECO-92. Exemplo disso, em 1984, durante a 16a reunião da Assembleia Geral da International Union for Conservation of Nature (IUCN), "iniciou-se a discussão sobre temas ligados a preservação da Biodiversidade que veio se concretizar na Convenção sobre Diversidade Biológica (CDB), assinada na Conferência das Nações Unidas para o Meio Ambiente - ECO-92 (GUARATINI, SUGIYAMA, et. al, 2010, p. 27).

Diante desse contexto, esta investigação se apoiou na seguinte questão: Que estilos de pensamento sobre biodiversidade circulam nos artigos do EPEA? O objetivo principal foi identificar os estilos de pensamento em pesquisas sobre biodiversidade circuladas no EPEA.

\section{METODOLOGIA}

A pesquisa envolveu artigos publicados do I EPEA ao VI EPEA. A seleção e análise dos artigos seguiu alguns elementos da análise de conteúdo prevista por Bardin (2009). A leitura dos artigos foi baseada na epistemologia de Ludwick Fleck nos moldes do estilo de pensamento fleckiano. 
Na seleção dos artigos foram utilizados os seguintes critérios: Primeiro os artigos deveriam conter a palavra "Biodiversidade" no título; depois os artigos deveriam conter a palavra "Biodiversidade" no título, nas palavras-chave, no resumo e nas referências. Nos artigos, a palavra Biodiversidade deveria apresentar uma discussão teórica sobre o tema: por isso, nem todos os artigos foram considerados relevantes para a pesquisa.

\section{RESULTADOS E DISCUSSÃO}

Os elementos do EP estão contidos na epistemologia fleckiana, e foram definidos por Cutolo (2001) e aplicados nesta pesquisa para identificar a postura dos artigos que abordam o tema Biodiversidade, determinação histórica do EPEA por meio dos grupos de discussão e pesquisa, momento processual da teoria científica, corpo de conhecimentos, caracterização do coletivo e formação específica dos autores que publicaram trabalhos no EPEA. A partir dessa estrutura, foi possível identificar os diferentes Estilos de Pensamento sobre Biodiversidade que circulam nos artigos do EPEA.

Nesta pesquisa, após a seleção dos artigos sobre Biodiversidade publicados nas seis edições do EPEA (do ano 2001 a 2011) identificamos seis artigos voltados para a educação formal e cinco em educação não formal (Quadro 1). Na educação formal, o tema Biodiversidade destacou-se em pesquisas relacionadas à percepção ambiental de alunos sobre Biodiversidade, abordagem dos livros didáticos sobre o tema e projeto de pesquisa sobre Biodiversidade em universidades. Os trabalhos publicados pelas universidades de Minas Gerais são, em sua maioria, relacionados ao contexto não escolar, enquanto os artigos das universidades de São Paulo estão mais relacionados ao ambiente escolar.

Os dados do quadro 1 apontam que a percentagem de artigos de biodiversidade em relação ao total por edição não foi significativa haja vista a relevância do estudo sobre a biodiversidade para a Educação Ambiental trata-se de temas que estão interligados e desenvolveram conceitos individuais que podem ser estudados por um coletivo de pesquisadores por isso são um fato cientifico. No entanto as pesquisas na área de biodiversidade ainda são mínimas em eventos de Educação Ambiental como o EPEA.

Acreditamos que a disparidade na percentagem dos artigos por edição no EPEA relaciona-se ao fato de não existir um Grupo de Discussão e Pesquisa- GDP sobre Biodiversidade por isso o tema ficou diluído no evento. Por outro lado, como o tema não ganhou destaque durante as seis edições do EPEA não foi criado um GDP específico para a biodiversidade, pois o GDP é criado a partir de temas relevantes da Educação Ambiental por isso, acreditamos que a biodiversidade merece ganhar esse espaço no EPEA para incentivar a produção de pesquisas nessa área.

Quadro 1: Análise geral dos artigos do EPEA sobre Biodiversidade.

\begin{tabular}{|c|c|c|c|c|}
\hline ENCONTRO & No de artigos/\% & $\begin{array}{l}\text { No de artigos de } \\
\text { educação formal }\end{array}$ & $\begin{array}{l}\text { № de artigos de } \\
\text { educação não formal }\end{array}$ & $\begin{array}{l}\text { № Total de artigos } \\
\text { Aprovados por EPEA }\end{array}$ \\
\hline I EPEA (2001) & $2(1,58 \%)$ & 1 & 1 & 79 \\
\hline II EPEA (2003) & $3(2,13 \%)$ & 2 & 1 & 72 \\
\hline III EPEA (2005) & $2(1,46 \%)$ & 2 & 0 & 87 \\
\hline IV EPEA (2007) & $1(0,87 \%)$ & 0 & 1 & 90 \\
\hline V EPEA (2009) & $2(1,8 \%)$ & 1 & 1 & \\
\hline
\end{tabular}




\begin{tabular}{|c|c|c|c|c|}
\hline VI EPEA (2011) & $1(0,88 \%)$ & 0 & 1 & 88 \\
\hline TOTAL & $\mathbf{1 1}$ & $\mathbf{6}$ & $\mathbf{5}$ & $\mathbf{4}$ \\
\hline
\end{tabular}

No I e II EPEA não foram disponibilizados grupos de discussão, no entanto, os trabalhos nesses dois encontros, mostram que o tema Biodiversidade foi inserido na Educação Ambiental formal e não formal. A partir do III EPEA introduziram-se grupos de discussão e pesquisa, assim temos artigos nos seguintes GDP: Educação Ambiental e o Contexto Escolar (2 artigos), Pesquisa em EA e Contextos Não Escolares (2 artigos), Pesquisa em Educação e Formação de Professores/educadores (1 artigo).

De acordo com a figura 1 os três primeiros encontros somam sete trabalhos e os três últimos totalizam quatro, ou seja, o tema biodiversidade perdeu força nas últimas edições do EPEA. A maior incidência de trabalhos sobre biodiversidade nos três primeiros encontros pode ser associada às políticas públicas e iniciativas do Ministério da Educação voltadas a Educação Ambiental quando surgem na proposta de Diretrizes Curriculares Nacionais para a Educação Ambiental: 1- Os parâmetros Curriculares Nacionais, elaborados em 1977, incluem, entre os temas transversais, o meio ambiente; 2- Os Parâmetros em AçãoMeio Ambiente na Escola e o Programa de Formação Continuada de professores, implementado em 1999; 3A inclusão da Educação Ambiental no Censo Escolar, em 2001; 4- A realização da I e II Conferência Nacional Infantojuvenil Pelo Meio Ambiente, desenvolvidas em 2003 e 2006 pelo Órgão Gestor da Política Nacional de Educação Ambiental; 4- A formação continuada de professores em Educação Ambiental no âmbito do Programa denominado Vamos Cuidar do Brasil com as Escolas.

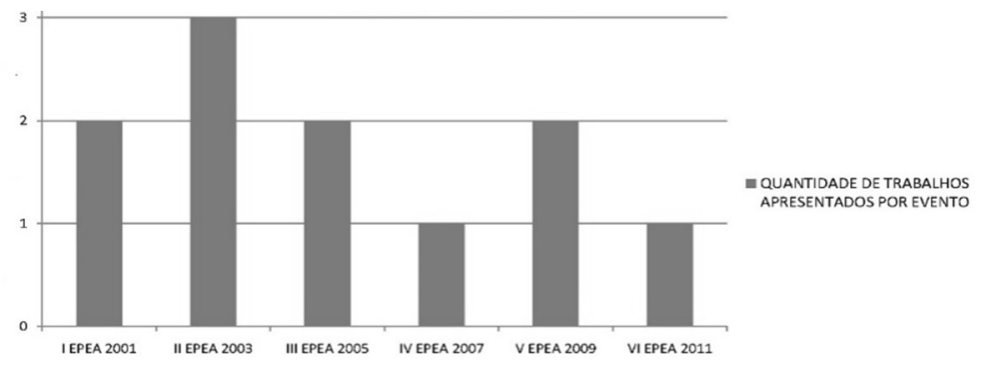

Figura 1: Quantitativo de trabalhos sobre diversidade apresentados no EPEA.

As ações descritas anteriormente contribuíram para o fortalecimento da Educação Ambiental no contexto escolar e o tema biodiversidade foi um dos temas ambientais. Dos sete artigos publicados nos três primeiros encontros do EPEA, cinco trataram a biodiversidade no ambiente escolar em virtude do movimento curricular que ocorria nas escolas brasileiras com o objetivo de incluir a Educação Ambiental como tema transversal no currículo escolar. O movimento inicia em 1998 com o lançamento da Política de Educação Ambiental e segue até 2006 com as conferências infanto-juvenis. Esses eventos abrangeram os anos de 2001, 2003 e 2005 que corresponde aos 3 primeiros encontros do EPEA.

Nas três últimas edições do EPEA ocorridas nos anos de 2007, 2009 e 2011 dos quatros trabalhos sobre biodiversidade, três foram de educação não formal e quatro de educação formal. A discussão Ambiental já estava presente nas escolas, e as atenções foram voltadas para 2010, chamado de o Ano Internacional da Biodiversidade, e para as comunidades tradicionais, práticas e culturas associadas a biodiversidade.

De acordo com a figura 1, o II EPEA apresentou maior quantidade de artigos (três). Esperava-se que 
na edição do VI EPEA, realizada no ano de 2011, tivesse maior número de publicações sobre o tema, visto que se tratava de um evento em pesquisas sobre Educação Ambiental, e a discussão intensificou-se em 2010, já que foi considerado pela ONU o Ano Internacional da Biodiversidade. Contudo, os dados não mostraram esse esperado.

Devido à abrangência do tema Biodiversidade, em todos os grupos de discussão houve discussão da temática em vários contextos: escolar, acadêmico, comunidades tradicionais, mídia impressa e televisiva. Isso indica a disseminação do tema Biodiversidade nas pesquisas as quais retratam estilos de Biodiversidade assumidos pelas várias instâncias sociais. Destacamos os artigos de mídia impressa e programas televisivos, pois são instrumentos de propagação de informações tidas como importantes referenciais pelo público em geral. Em relação à quantidade de universidades públicas e particulares que publicaram trabalhos nas seis edições do EPEA, é possível ter uma visão geral na figura 2.

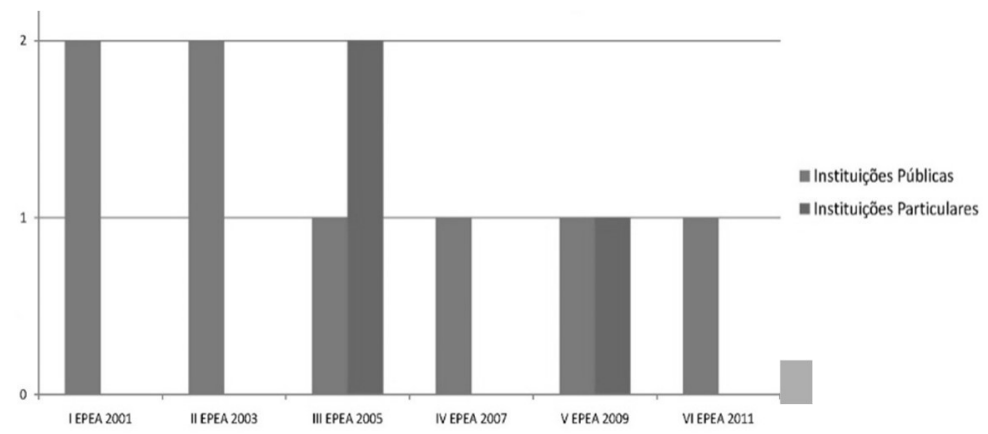

Figura 2: Quantitativos de instituições públicas e particulares que publicaram trabalhos nas seis edições do EPEA.

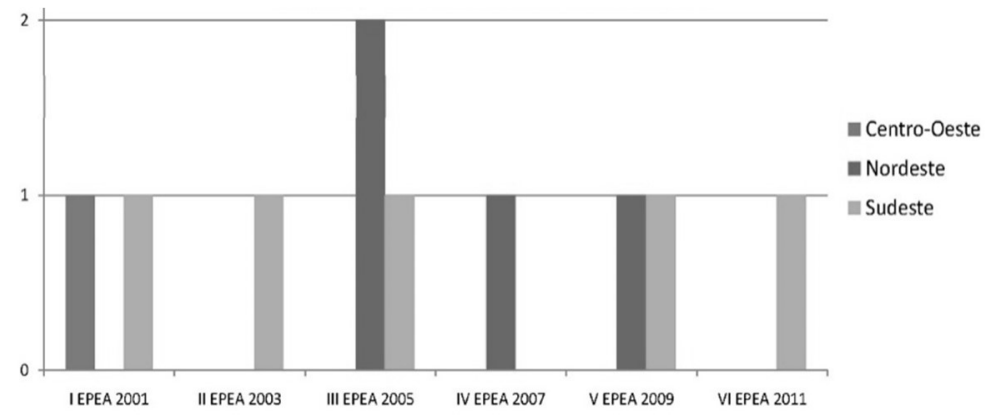

Figura 3: Regiões que publicaram trabalhos para o EPEA com o tema biodiversidade.

Com base na figura 3, é possível perceber que a região sudeste foi a que mais contribuiu com a temática no período de 2001 a 2011 com um total de cinco trabalhos. Os dados da pesquisa também revelam quais instituições correspondem a essa região: USP, UFU, UNIMEP, Faculdades Vale do Carangola/MG e Universidade Federal do ABC. Na região centro-oeste destacou-se a UFMT e na região Nordeste: UFS, UFPB, UESC e Faculdades Jorge Amado/Salvador, sendo que as duas últimas produziram trabalho juntas.

\section{Estilos de pensamento sobre biodiversidade}

O estilo de pensamento refere-se a uma epistemologia desenvolvida por Ludwick Fleck que foi médico, filósofo e sociólogo da ciência. Os estilos de pensamento são frutos de saberes diferentes, sendo que, cada grupo social possui um modo de observar uma atividade social. 
Os onze estilos que emergiram das análises não são correspondentes aos onze artigos de biodiversidade publicados no EPEA conforme descrição posterior. Além disso, também estão próximos das correntes ambientais definidas por Sauvé (2005), as tradicionais são as seguintes: naturalista; conservacionista/recursista; resolutiva; sistêmica; cientifica; humanista; moral/ética. As mais recentes são: holística; biorregionalista; práxica; crítica; feminista; etnográfica; da ecoeducação; da sustentabilidade e as representações de ambiente apresentadas por Reigota (2007) são, Naturalista, Conservacionista/Recursista, e Conscientizadora inclusive encontrei algumas correntes ambientais em textos de livros didáticos de biologia e geografia no artigo intitulado "Representações de Biodiversidade em livros didáticos" (SILVA e SILVA, 2012). Identificamos que o Coletivo de Pensamento no EPEA que compartilha o Estilo de Pensamento Naturalista/Biológico/Ecológico de Biodiversidade é formado pelos círculos exotérico e esotérico. O primeiro é restrito pois refere-se a um saber especializado sobre um determinado tema a exemplo da biodiversidade que foi o objeto de estudo dessa pesquisa. Já no círculo exotérico encontram-se os leigos instruídos, ou seja, possuem afinidade com o tema, mas não são especialistas. Portanto, o círculo esotérico é formado por especialistas em biodiversidade e o exotérico é formado por pessoas que possuem afinidade com o tema mas não são especialistas. Os autores dos artigos aprovados no EPEA, geralmente são biólogos que realizaram pesquisas em comunidades tradicionais sobre a fauna e a flora local, e, portanto, pela definição fleckiana fazem parte do círculo esotérico; já os estudantes entrevistados nas pesquisas pertencem ao círculo exotérico. Os dados apontam que "temos um coletivo de pensamento, quando duas ou mais pessoas trocam ideias: são coletivos momentâneos ou casuais de pensamento, que aparecem e desaparecem a cada momento" (FLECK, 2010, p.154).

Os resultados da pesquisa indicam que os membros do círculo exotérico, compartilham do Estilo de Pensamento biológico, com os seguintes termos: estudo da diversidade, estudo das espécies, diversidade do meio ambiente, flora e fauna do ambiente, diversidade da vida. Já os membros do círculo esotérico, compartilham o Estilo de Pensamento Biológico nos seguintes termos: identificação de espécies, diversidade de espécies, ecossistemas, sistemas biológicos. Apesar de essas palavras fazerem referência a conceitos ecológicos, os autores percebem as problemáticas socioambientais que afetam diretamente a Biodiversidade, apontando também para um estilo resolutivo de Biodiversidade, pois informa os problemas ambientais, tendo a preocupação de solucioná-los.

Os autores (Maria Edna Diniz, Maria Guiomar Carneiro Tomazello) dos artigos do EPEA utilizaram a seguinte reflexão ao se referirem às concepções dos estudantes: embora os alunos não conheçam o conceito de Biodiversidade, eles possuem certo entendimento sobre o tema, e em relação à análise dos livros didáticos de biologia do ensino fundamental abordados nos artigos do EPEA, os autores perceberam que não existe uma discussão aprofundada sobre a importância da Biodiversidade, sendo refletida na percepção dos alunos sobre a temática ambiental.

Identificamos o Estilo de Pensamento Ambiental Crítico ou Transformador vinculado a "uma prática social como tudo aquilo que se refere à criação humana na história, a educação ambiental necessita vincular os processos ecológicos aos sociais na leitura de mundo, na forma de intervir na realidade e de existir na 
natureza" (LOUREIRO, 2007, p. 66).

Esse estilo associa-se ao conceito de Biodiversidade do círculo esotérico rompendo com as ações conservadoras de Educação Ambiental que não fornecem condições de ação modificadora de indivíduos e grupos sociais. Vemos, pois, que não basta sensibilizar os discentes para a conservação de espécies, assim como não é suficiente o indivíduo ser parte da natureza. É necessária uma Educação Ambiental voltada para a formação de cidadãos onde as questões relacionadas à cultura, saúde, meio ambiente, saneamento sejam focos, tendo-se em vista que o homem é natureza, por isso, está ligado às questões socioambientais.

Em relação aos termos utilizados pelos membros que compartilham o Estilo de Pensamento Ambiental Crítico ou Transformador, destacam-se: ação transformadora e emancipatória, Educação Ambiental crítica, complexidade, global e multidimensional.

O Estilo de Pensamento Utilitarista de Biodiversidade encontra-se no círculo exotérico formado por comunidades tradicionais e autores de livros didáticos. Os primeiros externam a importância de se conservar as espécies animais e vegetais, pois são utilizados como alimento, remédios e fonte de renda; já os segundos não divergem muito desse pensamento, pois destacam que a perda da Biodiversidade também está associada a prejuízos econômicos, alimentícios e perda de oportunidades de se produzir remédios para doenças como a AIDS e o câncer. Em relação a esse pensamento, os autores do EPEA se manifestam com as seguintes expressões: visão antropocêntrica; textos sem questionamentos; é inadequada a abordagem sobre o tema Biodiversidade.

Já o Estilo de Pensamento Sistêmico está presente no círculo esotérico, quando os autores do EPEA destacam que os estudantes precisam compreender a natureza como um todo inter-relacionado, ou seja, não é possível que as diferentes formas de vida se desenvolvam isoladamente em um ambiente. Os autores do EPEA que retratam esse Estilo de Pensamento usam os seguintes termos: visão sistêmica da natureza e meio ambiente integrado.

O Estilo de Pensamento Científico foi evidenciado no círculo esotérico indicando produções acadêmicas referentes à Biodiversidade. As expressões mais utilizadas pelos autores do EPEA exprimem: a construção de um projeto coletivo sobre Biodiversidade; uma equipe de vocação biodiversa; estudos científicos sobre a Biodiversidade; Educação Ambiental e transformação do conhecimento científico em diferentes linguagens de materiais e de instrumentos didáticos.

O estilo Cultural e Humanista de Biodiversidade refere-se à circulação de ideias veiculadas por meio da mídia televisiva, portanto está no círculo exotérico: trata-se de imagens que retratam a construção cultural de natureza romântica com suas florestas, rios e mares. Diante dessa bela mata selvagem, ou seja, impenetrável, o homem surge desbravando e conquistando a natureza. Os termos que caracterizam esse estilo são: sentimento de harmonia, tranquilidade e paz, belas paisagens e desejo pelo desconhecido.

O estilo Patrimonial Ambiental. De acordo com Gonçalves (2014, p. 69) esse estilo considera a natureza, sociedade e cultura como ambiente patrimônio "constituído por fatores vivos, ecossistemas, povos e populações que habitam o Planeta Terra, nas suas dimensões naturais, sociais, culturais, simbólicas e afetivas." Os artigos do EPEA que apresentaram esse estilo trouxeram à tona a questão do ambiente 
enquanto patrimônio e viram a outros e a outras coisas como tal ou elemento constituinte do ambiente. Esse estilo está vinculado ao círculo esotérico de Biodiversidade, pois os autores focam a preservação do ambiente natural como garantia da qualidade de vida, e destacam o resgate do valor histórico inserido na relação homem-natureza, que está sendo discutida não somente no contexto escolar, mas adentrando nas comunidades tradicionais que possuem saberes, estes como fruto de heranças das gerações passadas e a convivência no ambiente natural. De acordo com Barros (2009, p.50) a Educação Patrimonial Ambiental consiste em

Educar para preservar o ambiente nos elementos que o compõem, os recursos naturais, os elementos não tangíveis do patrimônio cultural, o conhecimento, as técnicas, o saber e o saber fazer, o saber construir, as crenças, os usos e costumes de um povo, porque se deve transmitir às gerações futuras as referências de um tempo e de um espaço singular, possibilitando a intercomunicabilidade histórica.

Quanto aos termos utilizados pelos membros que compartilham esse Estilo de Pensamento, destaco os seguintes: conhecimento tradicional, patrimônio, lendas, comunidade tradicional, antepassados e direitos autorais pois permeiam as discussões desse estilo.

Outro Estilo de Pensamento presente nos artigos do EPEA é o Conservacionista, compartilhado pelo círculo exotérico formado pelos alunos e autores de livros didáticos, que ressaltam a importância de se conservar a Biodiversidade. A linguagem estilizada desse grupo é a seguinte: conservação da mata, conservação da fauna e flora, conservação dos recursos naturais. A representação social vinculada a esse estilo é a de se conservar a Biodiversidade para utilizar os seus recursos. Tal modo de pensar está muito próximo da representação utilitarista de Biodiversidade.

O Estilo de Pensamento Sustentável também emergiu nos artigos do EPEA no círculo esotérico, que destaca a importância da relação harmônica entre o homem e a natureza. "É um conceito oriundo das ciências biológicas e se refere à capacidade de suporte de um ecossistema, permitindo sua reprodução ou permanência no tempo." (LOUREIRO, 2014, p.13). Destaca que o homem pode utilizar a biodiversidade de modo economicamente viável, socialmente justo e ecologicamente correto. A linguagem estilizada desse coletivo de pensamento refere-se à integração equilibrada, desenvolvimento sustentável e sensibilidade ambiental. Nesse contexto, os Estilos de Pensamento contribuíram para a identificação das ideias circuladas sobre Biodiversidade no Encontro de Pesquisa em Educação Ambiental - EPEA, conforme proposto na problemática dessa investigação.

As análises objetivaram a resposta do problema de pesquisa, pois foram identificados 11 Estilos de Pensamento sobre o tema Biodiversidade que circulam nos coletivos de pensamento, formados pelos círculos esotérico e exotérico. Tendo em vista, que essa pesquisa constatou um déficit na produção de trabalhos científicos sobre biodiversidade, o tema não ganhou destaque para que possibilitasse a criação de um GDP sobre biodiversidade no EPEA, por outro lado sem um GDP a temática fica diluída no evento. Em relação a análise dos artigos identifiquei 4 estilos tradicionais conforme a descrição do quadro 2. 
Quadro 2: Estilos tradicionais de biodiversidade.

\begin{tabular}{|c|c|c|c|}
\hline No & ESTILO & QUANTIDADE DE ARTIGOS & EPEA \\
\hline 1 & Utilitarista & 4 & I, III, IV. \\
\hline 2 & Naturalista & 5 & I, II, III, V \\
\hline 3 & Conservacionista & 2 & III \\
\hline 4 & Resolutivo & 1 & V \\
\hline
\end{tabular}

Para fins de esclarecimento referentes ao quadro 2 adiciono que o estilo utilitarista foi manifestado em 2 artigos publicados no I encontro e os demais no III e IV. Já o naturalista ocorreu em 2 artigos publicados no I EPEA no II, III e V Encontro. Nota-se que os estilos tradicionais de biodiversidade predominaram nos artigos do EPEA, demonstrando que alguns pesquisadores ainda possuem uma visão biologizante, ecológica e conservadora de biodiversidade. No universo de 11 artigos sobre biodiversidade houveram 12 ocorrências de estilos tradicionais, ou seja, estiveram presentes em mais de $50 \%$ dos trabalhos apresentados no EPEA. Portanto é necessário que as discussões sobre biodiversidade sejam ampliadas no ambiente acadêmico. Visto que, o número de estilos mais críticos foram apenas 3: 1- Patrimonial Ambiental- que ocorreu em 2 artigos publicados no I e IV EPEA; 2- Sistêmico- Ocorreu em 1 artigo publicado no I EPEA; 3- Ambiental Críticaocorreu em 2 artigos publicados no I e IV EPEA.

Conforme a descrição anterior houve apenas 5 ocorrências de estilos mais críticos de biodiversidade nos artigos do EPEA. Mais uma constatação que explica porque não existe um GDP sobre biodiversidade no EPEA, tendo em vista que as ideias relacionadas a biodiversidade ainda estão associadas a conceitos ecológicos. Identifiquei ainda, mais quatro estilos que os classifiquei como intermediários pois não são tradicionais e nem críticos.

Quadro 3: Estilos Intermediários.

\begin{tabular}{|l|l|l|l|}
\hline \multicolumn{1}{|c|}{ No } & \multicolumn{1}{c|}{ ESTILO } & QUANTIDADE DE ARTIGOS & \multicolumn{1}{c|}{ EPEA } \\
\hline 1 & Humanista & 3 & IIII, IV, VI \\
\hline 2 & Cultural & 1 & II \\
\hline 3 & Científico & 1 & II \\
\hline 4 & Sustentável & 1 & $\mathrm{~V}$ \\
\hline
\end{tabular}

O estilo humanista admite a presença humana interagindo com a biodiversidade mas geralmente é atribuída ao homem uma imagem negativa, pois a ênfase está nos impactos ambientais.

Ao mesmo tempo que se evoca o exemplo de comunidades indígenas como modelo e paradigma da relação homem-natureza. E aqui cabe a interrogação: não são os indígenas homens? ... De que tipo de homem estamos falando quando se afirma que o homem está destruindo a natureza? Claro que quando se trata dos indígenas está-se falando de uma outra sociedade- de uma outra organização social, de uma outra cultura. Ora se isto é verdadeiro, não são os homens enquanto categoria genérica que estão destruindo a natureza, mas sim o homem sob determinadas formas de organização social no seio de uma cultura (PORTO, 1993, p. 75).

O estilo cultural assemelha-se ao estilo humanista pois culturalmente foi convencionado que o homem interfere de forma negativa na natureza. No entanto,

Quando evocamos o indígena como modelo estamos remetendo para a ideia de um passado idealizado, de um paraíso perdido, de um "bom selvagem". É como se tratasse da lembrança de uma infância, boa por natureza que foi pervertida no seu processo de desenvolvimento civilizatório... (PORTO, 1993, p. 75) 
Nesse contexto também existe uma ideia culturalmente construída. Portanto, nota-se que a relação homem-natureza nem sempre é destrutiva para o ambiente.

Se a nossa sociedade cultura institui a forma presente de relação com a natureza e dos homens entre si, é necessário percebermos que esse conceito de natureza e de homem que temos não é mais nem menos natural que qualquer outro e se ele não nos agrada, temos de superá-lo através de um pensar e de um agir mais lúcidos. (PORTO, 1993, p. 76)

O estilo científico discute a biodiversidade em instituições de ensino superior por meio de grupos de estudos cujos membros são de vocação diversas. Esses estilos tiveram 6 ocorrências nos artigos do EPEA e quiçá mesclados a outras ideias poderão resultar em outros estilos. Nesse contexto, espera-se que as discussões sobre biodiversidade possam evoluir para estilos mais críticos que possibilite a criação de um GDP sobre biodiversidade no EPEA.

\section{CONCLUSÕES}

Os estilos de pensamento identificados nos artigos do EPEA indicam um corpo de conhecimento e práticas composto por um coletivo de pensamento no círculo esotérico que realizam pesquisas sobre o tema biodiversidade.

Os artigos do I ao VI EPEA mostraram onze estilos de pensamento sobre biodiversidade: 1Biológico/Ecológico/Naturalista- discutem-se apenas os aspectos biológicos, ecológicos e naturais de Biodiversidade, ou seja, uma visão contemplativa; 2-Utilitarista- A Biodiversidade é valorizada devido aos benefícios que dispõem ao homem; 3-Patrimonial Ambiental- A Biodiversidade é um patrimônio natural associado a conhecimentos tradicionais transmitidos a várias gerações, e também é objeto de estudo de cientistas que procuram a cura para várias doenças por meio de plantas medicinais; 4-Sistêmico- Consiste em compreender a Biodiversidade por meio de várias relações que podem ser sociais, naturais, históricas, entre outras; 5-Científico- Está relacionado a estudos científicos sobre Biodiversidade; 6-Humanista- Existe interferência humana causando impactos a biodiversidade;7-Cultural-A Biodiversidade é vista como algo que deve ser conquistado pelo colonizador; 8-Resolutivo- Está relacionado às possíveis soluções para conservar a Biodiversidade; 9-Sustentável- Propõem uma relação harmoniosa entre o homem e a natureza; 10Ambiental Crítica- Ação capaz de contribuir com a transformação de uma realidade que, historicamente, se coloca em uma grave crise socioambiental; 11-Conservacionista- Preocupa-se com a conservação da Biodiversidade.

A epistemologia de Fleck possibilitou verificar as discussões que ocorrem no interior do coletivo de pensamento como o modo de ver, entender e conceber. Trata-se de um ver orientado, formativo, estilizado, essencial para a sustentação do estilo que também é determinado sócio, histórico, cultural e psicologicamente referindo-se a ciência como um processo coletivo que depende de fatores externos bem como, processual, dinâmico, sujeito a mecanismos de regulação.

Percebemos que seis eventos do EPEA acontece um saber que se modifica, que é mutável posto que novos estilos de pensamentos vão surgindo e ao mesmo tempo se modificando, uma vez que são influenciados pelo avanço da ciência, por instrumentos, teorias, métodos, modelos e técnicas que por sua 
vez influenciam um coletivo de pensamento.

\section{REFERÊNCIAS}

ALVARENGA, L. C. A.; NOGUEIRA FILHO, S. L. G.. Escalas de Avaliação de Sentimentos: Um Novo Instrumento para os Projetos de Educação Ambiental. In: Encontro de Pesquisa em Educação Ambiental, 3. EPEA, Ribeirão Preto: 2005.

BARDIN, L.. Análise de Conteúdo. Rio de Janeiro: Edições 70, 2009.

BARROS, J. V.. Representações Sociais do Ambiente do Igarapé da Rocinha como Patrimônio por crianças das Séries Iniciais. Dissertação (Mestrado em Educação em Ciências e Matemáticas) - NPADC-UFPA, Belém, 2008.

DINIZ, M. E.; TOMAZELLO, M. G. C.. Um estudo sobre o Tema Biodiversidade em Livros Didáticos de Ciências do Ensino Fundamental. In: Encontro de Pesquisa em Educação Ambiental- EPEA, Ribeirão Preto: 2005.

FLECK, L.. Gênese e Desenvolvimento de um fato Científico. Belo Horizonte: Fabrefactum, 2010.

GADOTTI, M.. A questão da Educação Formal/ Não Formal. 2005.

GUARATINI, S.. Cadernos de Educação Ambiental. 4.

Biodiversidade. São Paulo: SMA, 2010.

GONÇALVES, A. C.. A Circulação de ideias sobre Biodiversidade por professores de Ciências e Biologia nas abordagens CTS e Patrimonial Ambiental. (Dissertação de Mestrado). Belém: 2014.

GONÇALVES, C. W. P.. Os Descaminhos do Meio Ambiente. São Paulo: Contexto, 1993.

GUIDO, L. F. E.. Imagens de Educação Ambiental na TV: O Repórter ECO. In: Encontro de Pesquisa em Educação Ambiental, 2. EPEA, CD-ROM. Arquivo: 50. São Carlos: UFSCAR, 2003.

JUNIOR, S.; VIEIRA, S.; SOARES, P.; SATO, M.. Resgatando a Biodiversidade de uma Comunidade Tradicional Pantaneira. In: Encontro de Pesquisa em Educação Ambiental- EPEA, CD-Rom arquivo: TR 65. Rio Claro: UNESP, 2001.

LEITE, M. M. B. X.. Educação Ambiental e Resistência: O Caso Mosqueiro (Aracaju/SE). In: Encontro de Pesquisa em Educação Ambiental, 4. EPEA, UNESP-Rio Claro, 2007.

LOPES, L. P.; ALBUQUERQUE, M. L. F. ; ABÍLIO, F. J. P. Percepção Ambiental dos Discentes de Ensino Médio de uma Escola Pública de João Pessoa-PB sobre Temáticas Ambientais e Biodiversidade. In: Encontro de Pesquisa em Educação Ambiental, 5. São Carlos: EPEA, 2009.

LORENZETTI; MUENCHEN; SLONGO. A Contribuição Epistemológica de Ludwick Fleck na Produção Acadêmica em Educação em Ciências. 2011.
LOUREIRO, C. F. B.. Sustentabilidade e Educação: Em defesa da Educação Ambiental no Brasil. In: Políticas e Práticas de Educação Ambiental na Amazônia: das Unidades de Conservação aos Empreendimentos Econômicos. Belém: UFPA; GEAM, 2014.

MEC. Coordenação Geral de Educação Ambiental; MMA. Departamento de Educação Ambiental. Vamos Cuidar do Brasil: Conceitos e Práticas em educação ambiental na escola. UNESCO, 2007.

MOURA, R. H.; SILVA, F. D.; BRANDÃO, C. R.. Biodiversidade, Sustentabilidade e Educação Ambiental no Estado de São Paulo: a história de criação de um projeto coletivo e a sua proposta. In: Encontro de Pesquisa em Educação Ambiental, 2. EPEA, CD-ROM: Arquivo 09. São Carlos: UFSCAR, 2003.

MOREIRA, L. S.; BARBOSA, G. S.. Diagnóstico Socioambiental das Comunidades do Entorno do Parque do Brigadeiro/MGOlhares Iniciais Sobre o Projeto Serra do Brigadeiro: Montanhas dos Muriquis. V Encontro de Pesquisa em Educação Ambiental-EPEA, São Carlos: 2011

PRATES; V.. A Construção do Conceito de Biodiversidade por Estudantes da 6a série (3 ciclo) do Ensino Fundamental de uma Unidade de Ensino Particular. II Encontro de Pesquisa em Educação Ambiental: abordagens epistemológicas e metodológicas. São Carlos: UFSCar, 2003.

REIGOTA, M.. Meio Ambiente e representação social. 7 ed. São Paulo: Cortez, 2007.

RODRIGUES, M. S.; CUNHA, A. M.. Fauna e Flora do Cerrado: Conhecimentos dos Alunos do Ensino Médio de uma Escola Pública do Triângulo Mineiro. In: Encontro de Pesquisa em Educação Ambiental, CD-ROM TR 75. São Carlos: 2001.

SAUVÉ, L.. Uma cartografia das correntes em educação ambiental. In: SATO; CARVALHO. Educação Ambiental Pesquisas e desafios. Porto Alegre: Artmed, 2005.

SILVA, E. H. S. S.; M. F. V.. Representações de Biodiversidade nos livros Didáticos. In: Simpósio em Educação em Ciências, 2. SECAM. Manaus, 2012.

SILVA, E. H. S. S.; M. F. V.. Estilos de Pensamento de Biodiversidade em Pesquisas de Educação Ambiental Publicadas no EPEA. (Dissertação de Mestrado). Belém, 2014.

SILVA, L. C. S.; FERREIRA, R. L. F.. Abordagem de Biodiversidade em Artigos de Mídia Impressa e Possibilidades de Contextualização na Perspectiva da Educação Ambiental Crítica. VI Encontro "Pesquisa em Educação Ambiental" A Pesquisa em Educação Ambiental e a Pós-Graduação no Brasil Ribeirão Preto, 2001. 